\title{
Colonic Perforation, CTCAE
}

National Cancer Institute

\section{Source}

National Cancer Institute. Colonic Perforation, CT CAE. NCI Thesaurus. Code C143376.

A disorder characterized by a rupture in the colonic wall. 